\title{
Vascular Emergencies - The New COVID-19 Crisis?
}

\author{
Pradeep Narayan ${ }^{1}$ and Gianni Angelini² \\ ${ }^{1}$ Rabindranath Tagore International Institute of Cardiac Sciences \\ ${ }^{2}$ Bristol University
}

September 16, 2020

\begin{abstract}
The authors in this manuscript have reported an increase in the number of vascular emergencies seen during the early phase of the COVID-19 pandemic in the Lombardy region of Italy. A significant increase in the number of acute limb ischaemia was seen during this phase along with other vascular emergencies. In this review, we have tried to examine this association between increase in vascular emergencies and COVID-19 infection. We have also described the differences in presentations, prognosis and procedural outcomes following operative interventions in these patients compared to the non-COVID patients. An attempt has been made to assess the role of adjunctive measures like intravenous heparin to improve outcomes.
\end{abstract}

\section{Vascular Emergencies - The New COVID-19 Crisis?}

Pradeep Narayan FRCS[CTh]*, Gianni D Angelini FRCS^

*NH Rabindranath Tagore International Institute of Cardiac Sciences, Kolkata, India

Short Title: Vascular emergencies in the COVID era

Word Count : 1250

\section{Corresponding Author:}

Prof GD Angelini, MD,MCh,FRCS, FMedSci

British Heart Foundation Professor of Cardiac Surgery,

Bristol Heart Institute Bristol Royal Infirmary,

Upper Maudlin Street BS2 8HW

Bristol, UK

G.D.Angelini@bristol.ac.uk

Conflict of Interest: none

Funding: This work was supported by the British Heart Foundation and the NIHR Biomedical Research Centre at University Hospitals Bristol and Weston NHS Foundation Trust and the University of Bristol.

Key words: COVID-19, Cardiac Surgery, Vascular emergencies, Acute Limb Ischemia, DVT

While the main presentation and focus of the Corona Virus Disease 2019 (COVID-19) has been lung injury, many other presentations have been reported since the start of the pandemic. The authors in this very pertinent and informative manuscript report the successful implementation of the "Hub-and-Spoke" model of health care delivery for vascular services in Lombardy, Italy during the early phase of the pandemic. More importantly they have reported an increase in the number of vascular emergencies seen in this phase. The 
authors have further tried to explore if there is an association between this increase in vascular cases and the current COVID-19 pandemic. ${ }^{1}$

The spectrum of vascular involvement experienced in the different "Hub" and "Spoke" hospital was varied. In the author's own institution which was a "Spoke" hospital, vascular presentation was mainly for aortic pathology. However, the "Hub" hospitals reported a significantly higher and unusual number of acute limb ischemia and amputations. ${ }^{2,3}$ Seventeen cases of symptomatic carotid artery stenosis requiring carotid endarterectomy were also reported over a 7 -week period at another "Hub" hospital. ${ }^{4}$ Besides, an increase in the number of venous thrombosis and thrombo-embolism was reported as well. ${ }^{5,6}$

This increase in the number of vascular cases, majority of them requiring urgent attention, is a very interesting observation and deserves in-depth examination. Apart from assessing if this increase was driven by COVID19 we also must evaluate these cases for any differences in terms of presentations, pathogenesis, prognosis, and outcomes of operative interventions compared to non-COVID-19 patients.

While it is tempting to ascribe it to the "Hub and Spoke" model of service delivery for vascular emergencies and argue that the increase in limb ischemia was secondary to concentration of vascular emergencies at the "Hub" hospitals it is quite likely that there is indeed "a vascular story" as the authors describe it, in COVID-19 patients. When the number of cases reported at one of the "Hub" hospitals was compared with the preceding year it was seen that the increase was as high as nine times the volume reported during the same period in the preceding year. Similar increase was also seen in another "Hub" hospital which reported a seven-fold increase in the incidence of limb threatening ischemia. ${ }^{4}$ This kind of increase is unlikely to be the effect of the "Hub and Spoke model" alone. Moreover, this is not a phenomenon that is unique to Lombardy but is getting reported increasingly from other parts of the world too where different healthcare delivery models exist. There are several reports from other centres of young, non-atherosclerotic patients with COVID-19 presenting with upper and bilateral lower limb ischemia as well as large-vessel strokes. ${ }^{7,8}$

It is also not the arterial system alone that seems to be affected by COVID-19. In keeping with the authors' observations, an increase in the prevalence of deep vein thrombosis (DVT) and venous-thromboembolism among COVID-19 patients has also been reported worldwide. ${ }^{5,6}$ DVT has been reported to be as high as $46 \%$ and in the ITU setting, is four times more common in patients with COVID-19, compared to those without it. ${ }^{9,10}$ Pooled data from 12 studies have reported the risk of venous thrombo-embolism to be $38 \%$ in these cases despite prophylactic or therapeutic anti-coagulation indicating a high risk of thromboprophylaxis failure. ${ }^{11}$ In a small early autopsy study in COVID-19 deaths, unsuspected deep vein thrombosis was found in 58\% of COVID-19 patients, and pulmonary embolism was the cause of death in one-third of the patients. ${ }^{12}$

In fact as evidence grows it is now becoming apparent that the pathogenesis of organ dysfunction (lungs, kidneys, liver and gastrointestinal system) in many of these patients was thrombotic in nature. ${ }^{13}$ And while the initial focus was mainly on micro-vascular thrombosis it now appears that there is high incidence of macro-vascular thrombosis as well as in COVID-19. A simple and clinically relevant explanation for increased thrombogenicity has been provided using Virchow's triad of hypercoagulability, stasis and endothelial injury. ${ }^{14}$ The vascular endothelium is the cornerstone of organ dysfunction and endothelial dysfunction results in a pro-thrombotic state which can lead to microthrombi formation as well as occlusion of bigger vessels. ${ }^{15}$ It has now been suggested that COVID-19 is due to immune-triggered, complement-mediated microangiopathy. ${ }^{13}$

The presentation of vascular involvement in COVID-19 as noted in the manuscript is extremely diverse. Apart from the aorto-iliac thrombosis and involvement of both proximal and distal limb vessels involvement of the Coronary artery, Subclavian artery, Cerebral and Carotid arteries, and mesenteric artery have all been reported. Similarly, apart from DVT, jugular and subclavian vein thrombosis as well as prostatic plexus thrombosis has been reported to occur in COVID-19 patients. ${ }^{6,8,12,15-17}$

What is especially worrying is the fact that limb ischemia is being reported in previously healthy patients with no co-morbidities or history of peripheral vascular disease. Not only that, even after successful thromboembolectomy and return of pedal pulses, recurrence of thrombosis within 2 hours have been reported in the 
absence of atherosclerotic disease.$^{7}$ Overall, the picture that emerges is that of a seriously deranged intravascular coagulation milieu and further illustrates that COVID-19 is associated with previously underestimated but an inherently high risk of thrombogenicity.

Need for re-intervention as well as lower than expected successful revascularization is another concern in management of these patients. ${ }^{2,4}$ The thrombus burden is significantly higher in these patients and there is a higher frequency of thromboses involving proximal vessels. Patients with symptoms of leg ischemia with concomitant COVID-19 infection are more likely to require amputation. This association was found to be true even after adjustment for peripheral vascular disease. The likely hood of death is also significantly higher in these patients. In presence of leg ischemia and COVID-19 infection presence of pulmonary or systemic symptoms put them at higher risk of adverse outcomes. ${ }^{16}$

Thus, not only has the incidence of acute limb ischemia actually increases in COVID-19 but the disease severity, prognosis and outcome following surgical revascularization are also quite different when compared to patients with limb ischemia without concomitant COVID-19 .

While there is enough evidence available to suggest the presence of an increased association between COVID19 infected patients and risk of venous and arterial thrombosis the understanding of measures to improve outcomes is currently lacking. There is some suggestion that heparin usage may be associated with better outcomes as one of the studies showed that no patient who had received intravenous heparin required re-intervention after revascularisation. Even though this was a small study and statistically it was not a significant association it was suggested that use of systemic heparin might improve surgical treatment efficacy, limb salvage, and overall survival. The benefit of heparin could be secondary to its anti-coagulant effect as well as its anti-inflammatory properties that include inhibitory interactions with multiple chemokines and complement. ${ }^{15,18}$ Moreover, heparin might also have anti-viral properties and prevents viral attachment by acting on the virus spike protein. ${ }^{19}$ Apart from anticoagulation the influence of antiviral treatment, complement inhibition, immune-suppression, plasma exchange and intravenous immunoglobulins have to be evaluated in future studies.

The authors in this manuscript have initiated a very relevant discussion and have raised several important questions. Based on the evidence there is no doubt that the vascular burden in general and limb ischemia in particular is significantly increased by COVID-19 infection. However, many unanswered questions remain, especially those pertaining to the management of this condition and improvement of outcome. Hopefully, future studies will help answer some of them.

References:

1. Bissacco D. Is there a vascular side of the story? Vascular consequences during COVID-19 outbreak in Lombardy, Italy. Journal of Cardiac Surgery.

2. Bellosta R, Luzzani L, Natalini G, Pegorer MA, Attisani L, Cossu LG, et al. Acute limb ischemia in patients with COVID-19 pneumonia. J Vasc Surg [Internet]. 2020 Apr 29 [cited 2020 Sep 9]; Available from: https://www.ncbi.nlm.nih.gov/pmc/articles/PMC7188654/

3. Melissano G, Mascia D, Baccellieri D, Kahlberg A, Bertoglio L, Rinaldi E, et al. Pattern of vascular disease in Lombardy, Italy, during the first month of the COVID-19 outbreak. J Vasc Surg. 2020 Jul;72(1):4-5.

4. Mascia D, Kahlberg A, Melloni A, Rinaldi E, Melissano G, Chiesa R. Single-Center Vascular Hub Experience after 7 weeks of COVID-19 Pandemic in Lombardy (Italy). Ann Vasc Surg. 2020 Aug 5;

5. Baccellieri D, Apruzzi L, Ardita V, Rinaldi E, Bertoglio L, Melissano G, et al. The "venous perspective" in Lombardia (Italy) during the first weeks of the COVID-19 epidemic. Phlebology. 2020;35(5):295-6.

6. Lodigiani C, Iapichino G, Carenzo L, Cecconi M, Ferrazzi P, Sebastian T, et al. Venous and arterial thromboembolic complications in COVID-19 patients admitted to an academic hospital in Milan, Italy. Thromb Res. 2020 Jul;191:9-14. 
7. Perini P, Nabulsi B, Massoni CB, Azzarone M, Freyrie A. Acute limb ischaemia in two young, nonatherosclerotic patients with COVID-19. The Lancet. 2020 May;395(10236):1546.

8. Oxley TJ, Mocco J, Majidi S, Kellner CP, Shoirah H, Singh IP, et al. Large-Vessel Stroke as a Presenting Feature of Covid-19 in the Young. N Engl J Med. 2020 May 14;382(20):e60.

9. Zhang Li, Feng Xiaokai, Zhang Danqing, Jiang Chunguo, Mei Heng, Wang Jing, et al. Deep Vein Thrombosis in Hospitalized Patients With COVID-19 in Wuhan, China. Circulation. 2020 Jul 14;142(2):11428.

10. Zerwes S, Hernandez Cancino F, Liebetrau D, Gosslau Y, Warm T, Märkl B, et al. [Increased risk of deep vein thrombosis in intensive care unit patients with CoViD-19 infections?-Preliminary data]. Chir Z Alle Geb Oper Medizen. 2020 Jul;91(7):588-94.

11. Hasan SS, Radford S, Kow CS, Zaidi STR. Venous thromboembolism in critically ill COVID-19 patients receiving prophylactic or therapeutic anticoagulation: a systematic review and meta-analysis. J Thromb Thrombolysis. 2020 Aug 3;1-8.

12. Demelo-Rodríguez P, Cervilla-Muñoz E, Ordieres-Ortega L, Parra-Virto A, Toledano-Macías M, ToledoSamaniego N, et al. Incidence of asymptomatic deep vein thrombosis in patients with COVID-19 pneumonia and elevated D-dimer levels. Thromb Res. 2020;192:23-6.

13. Merrill JT, Erkan D, Winakur J, James JA. Emerging evidence of a COVID-19 thrombotic syndrome has treatment implications. Nat Rev Rheumatol. 2020 Jul 30;1-9.

14. Ahmed S, Zimba O, Gasparyan AY. Thrombosis in Coronavirus disease 2019 (COVID-19) through the prism of Virchow's triad. Clin Rheumatol. 2020 Sep;39(9):2529-43.

15. Pons S, Fodil S, Azoulay E, Zafrani L. The vascular endothelium: the cornerstone of organ dysfunction in severe SARS-CoV-2 infection. Crit Care [Internet]. 2020 Jun 16 [cited 2020 Sep 11];24. Available from: https://www.ncbi.nlm.nih.gov/pmc/articles/PMC7296907/

16. Goldman IA, Ye K, Scheinfeld MH. Lower extremity arterial thrombosis associated with COVID-19 is characterized by greater thrombus burden and increased rate of amputation and death. Radiology. 2020 Jul $16 ; 202348$.

17. Wichmann D, Sperhake J-P, Lütgehetmann M, Steurer S, Edler C, Heinemann A, et al. Autopsy Findings and Venous Thromboembolism in Patients With COVID-19. Ann Intern Med [Internet]. 2020 May 6 [cited 2020 Sep 12]; Available from: https://www.ncbi.nlm.nih.gov/pmc/articles/PMC7240772/

18. Wada H, Matsumoto T, Suzuki K, Imai H, Katayama N, Iba T, et al. Differences and similarities between disseminated intravascular coagulation and thrombotic microangiopathy. Thromb J. 2018 Jul 11;16(1):14.

19. Mycroft-West C, Su D, Elli S, Guimond S, Miller G, Turnbull J, et al. The 2019 coronavirus (SARSCoV-2) surface protein (Spike) S1 Receptor Binding Domain undergoes conformational change upon heparin binding. bioRxiv. 2020 Mar 2;2020.02.29.971093. 